\title{
STATEWIDE INVENTORIES OF HERITAGE RESOURCES: MACRIS AND THE EXPERIENCE IN MASSACHUSETTS
}

\author{
P. H. Stott $\mathrm{a}^{\mathrm{a}}$ \\ a Massachusetts Historical Commission, 220 Morrissey Boulevard, Boston, MA 02125 - ph.stott@gmail.com
}

KEY WORDS: Cultural Heritage, Inventory, National Register of Historic Places, State Historic Preservation Office (SHPO), MACRIS, heritage databases, Massachusetts, interoperability

\begin{abstract}
:
The Massachusetts Historical Commission (MHC) is the State Historic Preservation Office for Massachusetts. Established in 1963, MHC has been inventorying historic properties for over half a century. Since 1987, it has maintained a heritage database, the Massachusetts Cultural Resource Information System, or MACRIS. Today MACRIS holds over 206,000 records from the 351 towns and cities across the Commonwealth. Since 2004, a selection of the more than 150 MACRIS fields has been available online at mhcmacris.net.

MACRIS is widely used by independent consultants preparing project review files, by MHC staff in its regulatory responsibilities, by local historical commissions monitoring threats to their communities, as well as by scholars, historical organizations, genealogists, property owners, reporters, and the general public interested in the history of the built environment.

In 2016 MACRIS began migration off of its three-decade old Pick multivalue database to SQL Server, and in 2017, the first redesign of its thirteen-year old web interface should start to improve usability. Longer-term improvements have the goal of standardizing terminology and ultimately bringing interoperability with other heritage databases closer to reality.
\end{abstract}

\section{HERITAGE INVENTORIES AND THE NATIONAL HISTORIC PRESERVATION ACT}

In 2016, the National Historic Preservation Act celebrated its Fiftieth Anniversary. This 1966 wide-ranging and profoundly important piece of legislation had three important consequences for heritage inventories: it greatly expanded the National Register of Historic Places as a national inventory program within the National Park Service; it defined criteria of significance for historic properties; and it created a network of state historic preservation offices (SHPOs) with a mandate to inventory the heritage of their states and territories. Federal (and later state) regulatory tie-ins to the National Register as a planning tool were designed to help avoid or minimize the adverse impacts of Federal undertakings; and after 1976, National Register designation became a commercial incentive to take advantage of tax benefits for the certified rehabilitation of National Registerlisted properties.

Statewide inventories were seen by the drafters of the 1966 Act as key to establishing the importance of individual resources and historic districts, ultimately providing baseline documentation against which properties could be evaluated for their significance. Knowing the range and variety of building types and styles, their designers, or their use would allow evaluation of their significance at local, state, and ultimately national scales. However, in the absence of strict direction, much less clear inventory guidelines from Washington, SHPOs have responded in different ways to the inventory expectation. Attempts to stimulate a common approach often met with hostility from SHPOs. Today, how states implement and manage their inventories varies widely. In 2006, the Preserve America Summit (New Orleans, 18-20 October) called for the expansion of current statewide inventories into a "national comprehensive inventory of historic properties" as one of its primary recommendations (NCSPO 2009). Followup surveys and interviews, however, found a very fragmented picture of the extent and health of statewide inventories, which invariably suffered from an absence of professional inhouse developers, lack of staff training, and lack of dedicated staff time. Furthermore, for many states, there was a strong resistance to reengineer systems in which they were already heavily invested, often with Federal money. Because of the wide range of models, there are few figures that allow more than anecdotal commentary or comparison. One very imperfect measure of SHPO activity is the number of listings in the National Register by State. As of 2015, the top five states with the largest number of National Register listings were New York (5774 listings), Massachusetts (4286), Ohio (3924), Kentucky (3385), and Pennsylvania (3377) [NPS 2015].

No attempt is made here to review various SHPO inventory programs or databases. Rather, it explores the design and evolution one of the pioneer heritage databases among SHPOs, the Massachusetts Cultural Resource Information System, or MACRIS. Begun in 1987, MACRIS today, with over 206,000 records, provides public access to one of the largest statewide inventories in the Federal preservation network.

\section{THE MASSACHUSETTS HISTORICAL COMMISSION HERITAGE INVENTORY PROGRAM}

The Massachusetts Historical Commission (MHC) was established in 1963, three years before the enactment of the National Historic Preservation Act (NHPA). Established as an office under the Secretary of the Commonwealth, the MHC was charged, among other responsibilities, with "advis[ing] the state secretary on matters relating to the historic assets of the commonwealth and [to] assist him in compiling and maintaining an inventory of such assets." [Chap. 697, Laws of 1963] Simultaneously, the same legislative act authorized the 351 towns and cities of the Commonwealth to establish their own 
historical commissions to conduct research into "places of historic value." Although the act made no mention of collaboration between municipalities and the MHC, in practice the process has been collaborative, with MHC providing standards and guidelines, and when available, funding for local survey efforts.

\section{Evolution of the Inventory Forms}

MHC's first inventory forms, which appeared in 1966, were one and two-sided printed forms for the "Area and Site Survey," and the "Structure Survey," ancestors of MHC's current 'Area' and 'Building' forms. Properties were described by circled multiplechoice responses (see fig. 1). In an era before wide-spread photocopying, a photograph of the property was designed to be attached to the upper left corner, inevitably covering the circled responses to thematic levels of significance. The only narrative opportunity was "a brief description of historic importance."

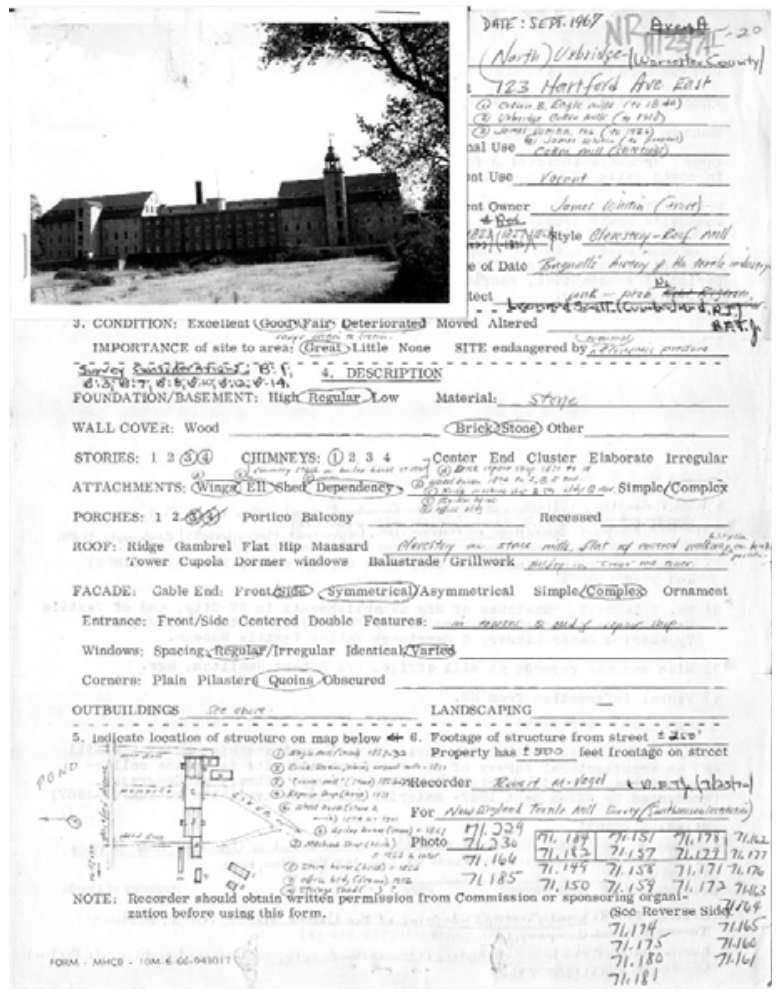

Figure 1. First generation Inventory form

Within a decade the multiple-choice format of the front side of the form had been replaced by fill-in-the-blank entries, and space dedicated for a photograph and locus map. Simultaneously, the suite of forms expanded, to include Objects (Form C, for outdoor sculpture and monuments), Burial Grounds (Form E), and Structures (Form F, for bridges and other engineering works). With the exception of Burial Grounds, all were based on the Resource Types already in use by the National Register. Forms for Streetscapes (Form G) and Parks and Landscapes (Form H) made their appearance about 1982, although the Streetscape form has since been discontinued and its data incorporated into Area forms. (Form D, for Historic Archaeological Sites and another form for pre-historic archaeological sites, are exclusively handled by MHC's Archaeological staff. Access to these sensitive records is restricted to qualified users.)

Information on the reverse side of the inventory forms has always been devoted to more narrative and bibliographic information. In the 1980s, the single "Historical Significance" paragraph was replaced by two separate text fields, encompassing description and significance. Today, descriptive text and historical narrative, with supporting figures and photographs, are often several pages in length, and detailed area forms can be as many as 30-40 pages long.

Much of the earliest inventory work was done by consultants hired directly by MHC, with a view to identifying the most distinctive features of the cultural landscape. High-style architectural landmarks, as well as selected monuments of the state's rich industrial heritage, were the focus of the early years. Since the federal Historic Preservation Fund (HPF) was established in 1976, MHC has used HPF funds for matching grants to cities and towns, allowing them to hire professional consultants to undertake town-wide historic resource surveys. In recent years, these funds have made possible 15-20 surveys annually. (In lean years, HPF funds have been limited to communities that met the Park Service qualifications of "Certified Local Governments.") Many towns and cities have also organized and funded their own professional surveys using MHC inventory forms, submitting a copy of the final product to MHC for inclusion in the Inventory, which has expanded in recent years by as many as 1000-1500 forms annually.

\section{Field and desk recording methods}

Heritage inventories nationally and internationally have evolved over the last fifty years, along with methods of recording and technology. Many of the earliest forms, often more reliant on description than on time-consuming historical research, often incorporated multiple-choice answers to questions of style and individual building features. As research tools improved, historical narrative and significance also took on a larger role. Today, although the multiple-choice format is making a comeback in field-based electronic recording techniques (especially in the urgent requirements of disaster management and in 'reconnaissance' surveys), online services (statewide GIS, assessors' records, deed registries and multiple online historical sources) make desk completion both more efficient and more comprehensive in order to establish both architectural and historical significance, once initial field photography and reconnaissance have been completed.

\section{THE MASSACHUSETTS CULTURAL RESOURCE INFORMATION SYSTEM (MACRIS)}

By the mid 1980s, MHC had over 100,000 paper forms, organized by municipality and the form's index number, assigned by surveyors at the time of completion. The forms were accessed through the use of a card catalogue organized by town and street address, providing the form's index number. While the card file could readily locate single records, identifying resources of similar type, style, or age, much less by the same architect, was not possible.

MHC began to seriously consider computerizing the inventory in the mid 1980s about the time that the State's Department of Environmental Quality Engineering (DEQE, now the Department of Environmental Protection) was looking for a means of tracking the effects of acid rain. With a grant from DEQE, MHC contracted with the database developer Data Basics, Inc. of Providence, RI to design a robust information system that would not only track above-ground inventory records, but would integrate other resource-related activities of the office, including National and State Register eligibility and 
status, Grants, Section 106 and tax act reviews. After extensive consultation, MHC chose the MultiValue database software Pick, in part because it required only one moderately sized computer, originally an IBM AT, which could be accessed from a dozen or more dummy terminals. (For the same reason, Pick was also the platform of choice in the 1980s and '90s for many library systems.)

From the start, MACRIS was planned to be more than a heritage database, eventually encompassing an event-based review and compliance log, Grants management, and a constituent database in addition to the heritage database with which it was launched. This review focuses exclusively on its management of MHC's heritage inventory. The original historic resource data entry screens included over 150 fields. Some were abstracted directly from the paper inventory form such as "Historic Name," address, style and acreage; others were inferred or required knowledge by the data entry team, such as Significance Period (choice of seven) or Congressional District. Often the questions, such as building form (footprint shape, 16 options), roof form (15 options), and bridge types (72 options) required examination of the attached photographs, or close reading of text narratives. Indeed, with the help of the Massachusetts Department of Public Works (now the Dept. of Transportation) Historic Bridge Specialist, an entire entry screen (and later a specialized Bridge Structure Form), was devoted to describing bridges. Another set of screens was developed for Burial Grounds.

Some fields, including the "materials" used in wall, trim, roof and foundation, were inherited from DEQE needs; others, river drainage area (260 options from a lookup table) or MHC Study area (8 large regions of the state), represented new opportunities to include information that could be readily obtained at the time of data entry. There were no full text fields, and (until 2016) the longest fields were only 80 characters in length. Controlled vocabularies established in 1987 and since expanded still govern the input of much of the data into the system.

\begin{tabular}{|l|}
\hline Use Types (125) \\
Areas of Significance (33) \\
Significance Periods (7) \\
Construction year (4 char. year) \\
Maker (free text) \\
Style (37) \\
Roof, wall, foundation materials (70) \\
Condition (6) \\
Structure (47) and Object (15) Subtypes \\
Designation Type (11) \\
Figure 2. Fields contributing to significance with \\
number of lookup options available
\end{tabular}

MACRIS included several fields immediately relevant to determining significance (Figure 2). With some modification, many of these fields (Use Types, Areas of Significance, Style) were adopted from those already in use by the National Register, often with fixed authority tables governing input and search choices, although usually Pick's multivalue fields allowed multiple terms for a given field response. (Figure 2) "Maker" (embracing architect, builder, designer, engineer, etc.), and construction year were free-text fields, but others, including Areas of Significance (33 options, including 'not researched' and 'other'), Use Types (125), and Architectural style (37 options) provided controlled ranges.
Critical to the program was the assignment of a unique resource code, variously referred to as an "MHC ID" or "MACRIS number," to each separate resource and area, using a three letter municipality code and a number, or letters for areas (e.g., BOS.12785, UXB.A). MHC IDs are the integrating common data link between most of MHC's Inventory, regulatory and grant activities.

The Massachusetts Cultural Information System, or MACRIS, was launched in July 1987 with a pilot entry of the inventory records of ten Massachusetts towns, initially chosen to provide DEQE with a test sample of data for acid rain studies (Litchfield 1988). With a limited data entry staff, and new forms being submitted all the time, it would take 20 years to complete data entry on the legacy inventory records. Since the original grant from DEQE, the continued maintenance and expansion of the system has been possible entirely with annual matching grants from the National Park Service's Historic Preservation Fund.

MACRIS went public in the summer of 2004, when a selection of its Pick fields was migrated to an online SQL database at mhcmacris.net. Refreshed weekly from Pick, "Web MACRIS" employs a multi-screen set of search tools, typical of many databases at the time: Location and Significance filters were given separate screens, while a third screen yielded the results of the filters. Individual "Record pages" could be selected from the "Results" page. The significance filters included separate dropdown options for Resource Type, Use Type, Architectural Style, and Significance. (Resource subtypes and materials are more recent additions.) Free-text fields were provided for Historic Name, 'Maker,' and Construction Year (Fig. 3).

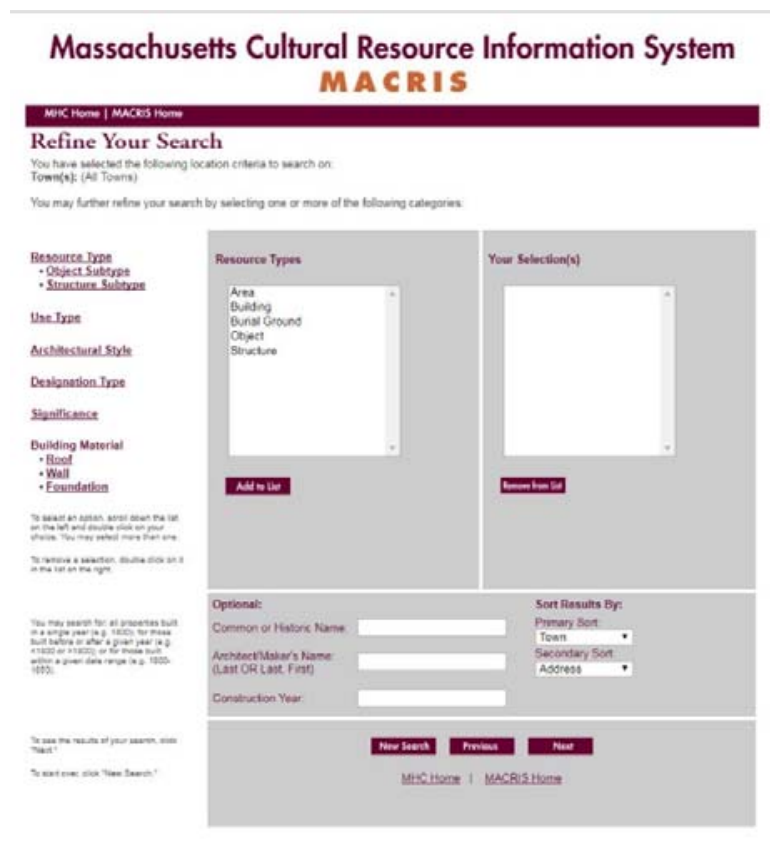

Figure 3. Web MACRIS Significance filter screen

Digitization of legacy files, 2008-2013

MACRIS was never intended to replace the paper inventory forms, but rather provide a capsule summary and detailed entry into them. Although MACRIS has not been strictly speaking, an "event-based" heritage database, paper inventory records preserve successive survey 'events' as well as the record of all evaluation decisions taken since the resource was first identified, 
thus preserving a record of changing conditions and evaluations.[1] To bring the full wealth of decades of inventory and evaluation online, four years after MACRIS went public, MHC began a digitization project of the original legacy inventory records. The original paper files were scanned by an outside vendor as grayscale multi-page PDF files, at 300 dpi. The "primary photograph" on each form was also digitized as a standalone JPG image. Each PDF file was character-recognized (acknowledging that handwritten forms, as well as some of the older photocopied forms would not benefit from OCR). Since 2006, however, most new forms are submitted in both paper and MS Word, together with separate JPG photos. (MHC's statutes still require submission and maintenance of paper records.) After internal review of, and minor edits to, new forms, the "born digital" files are converted directly to PDF and added to the public website. Updates to legacy forms are appended to the front of the existing PDF files, thus gradually minimizing the problem of older forms that are not searchable. Digitization of the legacy files was completed in 2013.

Since 2007, new nominations to the National Register of Historic Places have gone online within a few days of their official listing. Most older nominations are now also online in the MACRIS web site, becoming part of the body of PDFs ultimately capable of free-text searches.

\section{Data Entry and Staffing}

Data entry and uploading of files has been the responsibility of MHC's Survey \& Planning Division, and it is not expected that in the foreseeable future methods of data entry will significantly change. The advantages of manual data entry with which MACRIS was initiated 30 years ago provide quality control and supplemental data fields that it would not be practical or desirable to ask of external users. Technical maintenance and modifications to the webpage design are the responsibility of outside database consultants. [2]

\section{MACRIS Maps}

Soon after the launch MACRIS, MHC began an inhouse digitization of historic and archaeological resource geographic information into a geographic information system, the Caliper Corporation's 'Maptitude,' (and later 'Maptitude for the Web'). Initially, digitization was part-time work for staff normally assigned to other projects. It look advantage of the newly created MHC IDs to link spatial data to inventory records. Unlike, MACRIS, however, it was accessible only from a single terminal. MHC's GIS development was given its first full-time staff in the early 2000s. Although full digitization of legacy points was not completed until 2016, MACRIS Maps was ported to the web in 2007 as maps.mhc-macris.net. Historic resource map layers are also shared with the statewide GIS server, MassGIS. (Archaeological resource layers are available to qualified users with a separate login.) Today digitization employs the opensource software application QGIS and is running on the web using GeoServer. MACRIS and MACRIS Maps are not yet fully integrated: although MACRIS Maps links spatial information to the online MACRIS site, MACRIS does not yet report the results on searches back into MACRIS Maps. It is anticipated that this integration will be one of the first objects of the redesigned system as MHC moves forward. (Figure 4).

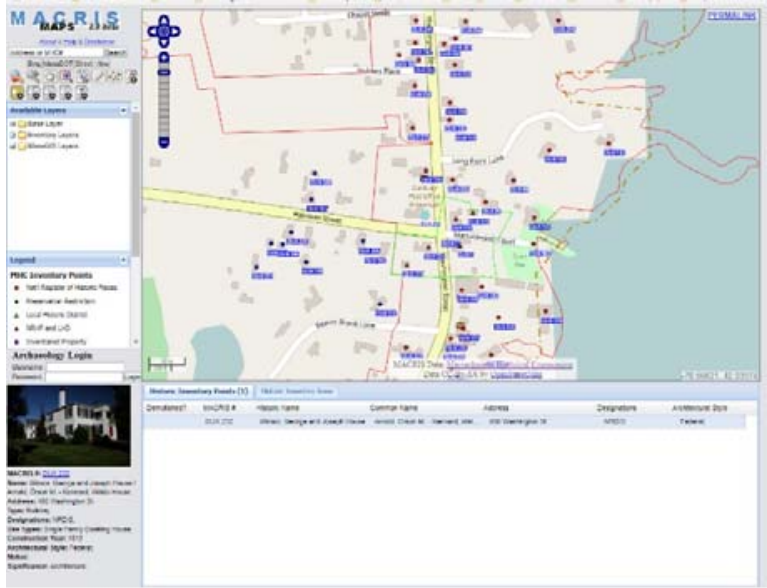

Figure 4. MACRIS Maps screen

\section{MOVING FORWARD}

In 2016, after nearly three decades in Pick, MACRIS moved to a new software platform, SQL Server ("MACRIS 2"). Today, however, even staff with access to the internal database are more likely to use Web MACRIS for day-to-day resource queries, thanks in part to quick access to scanned records. To streamline this access, in 2017 MHC expects to redesign its public MACRIS website. The initial changes are expected to largely update and modernize the interface to the data, without losing the full search opportunities currently offered. It is expected that filters and results will appear on the same page, allowing quick confirmation of the search query. Ideally, search results will be returned in both tabular and spatial form with a screen from MACRIS maps. Full text search capacity, of both inventory and National Register record PDFs will greatly expand access to the wealth of research accumulated over the past half century.

How to expand access of the rich resource base is the subject of ongoing discussions. For instance, one demand from outside consultants is for better access to data on architects: many inventory and National Register forms have well-researched discussions of individual designers or firms, but while MACRIS allows selection of all of the resources with which that designer is associated, determining which record (of sometimes dozens of records) has the most valuable research to mine is less easy without opening each record in turn. A separate architect's module, with birth and death dates, brief biography, and links to their work should be a real possibility.

Only approximately eighteen of almost 180 fields in use in MACRIS have been exported to the public MACRIS web site; the redesign will examine whether additional fields would aid searches. "Record date," displaying the date the information on a particular site was last updated; National Register significance level (national, state, local) or Criteria (A,B,C,D); or Significance Periods are among the fields that could be part of an 'advanced search' screen.

As the fields are currently organized in MACRIS, Styles (37 options), Areas of Significance (33), and Use Types (125) are each offered in unstructured alphabetical order. Since most users are unfamiliar with the ranges of options, structured lists would make these fields much easier to search. Structuring "Use Types," for instance, under a more limited number of "categories" or "classes" would also make it easier to identify 
omissions or potential redundancy. The National Register uses fourteen principal categories to group 92 use types; Historic England's "Monument Types" Thesaurus uses 18 classes and multiple subclasses to group a list of 125 pages of building, structure and site types. Illustrated modules could be developed to define each of the use types, styles, or areas of significance, functioning in a similar way to an 'architects module,' described above. A useful model is the successful Flanders Heritage Inventory (https://inventaris.onroerenderfgoed.be/), combining a robust thesaurus and thematic and biographic modules.

Currently, MHC has no means of tracking usage of the MACRIS site, or to query and monitor how often search fields are used. This limits the agency's ability to improve search queries or improve access to less-used tools. (Unknown, for instance, are questions such as the means by which users enter MACRIS - by default welcome screen or direct link to Location Search screen, or to a specific record page? What are typical significance or date queries? What filters are most or least frequently used?)

Another object of the redesign would make MACRIS and MACRIS maps accessible from smart phones and tablets. And while the development of mobile apps is not currently in MHC's mission, a redesigned web interface would encourage outside developers to create a MACRIS map app with GPS sensitivity, making possible MACRIS-driven walking tours of historic places and districts. Designated properties, such as National Register sites or local landmarks could be augmented by separate free text summary fields, like those already adopted by the National Register in its weekly list of recently listed properties.

\section{Interoperability}

In 1966, the National Historic Preservation Act called for the identification of the nation's historic resources. On the Act's 40th anniversary, the Preserve America Summit reiterated this call with a demand for a "national comprehensive inventory." Today, just past the 50th anniversary, we are no closer to this 'Holy Grail' of heritage identification. Cross-platform searches interoperability -remains elusive and beyond the ability of most players to implement. In this writer's opinion, national standard setting organizations, whether the National Park Service, the National Conference of State Historic Preservation Officers or other independent non-profit institutions with a standard-setting agenda, could develop a "federated search" ability to search across participating databases of similar resources. (Historic England's HeritageGateway (http://www.heritagegateway.org. uk/gateway/) is such a "front-end" search facility across over 60 databases with full access to its Monument Types.) Today, however, the trend in database construction, among library web searches and increasingly among heritage databases, seems often to follow the Google lead, with a single "unified" search box, expected to search multiple fields. (There is nothing more discouraging than a search for the architect "Chambers, William" in a single unified search box which retrieves "City Chambers" or "9-15 Chambers St" as results.) "Advanced search" usually offers very few additional field options. By seeking to simplify searches to appeal to a broader public we may often hide the wealth that lies in our heritage databases. It often seems that heritage database designers come from a tech environment and have limited experience in the research queries that users will need. Most heritage databases are also limited to the geographic region of their agency's remit.

If we truly value the resources represented in heritage databases, it is important not only to make them searchable by as wide a variety search terms as possible, but to share that wealth across data sets. In this respect, the work of the Forum on Information Standards in Heritage (FISH) has been notable and deserves to be better known outside the United Kingdom and CIPA (MIDAS 2012).

\section{REFERENCES}

Litchfield, Lestra, (1988) "MHC Inventory to be Computerized," Massachusetts Historical Commission Newsletter 14:1.

Massachusetts Historical Commission, Historic Properties Survey Manual: Guidelines for the Identification of Historical and Archaeological Resources in Massachusetts. [Boston: Massachusetts Historical Commission] July 1992; revised Sept. 1993; Sept. 1995.

MIDAS Heritage -- The UK Historic Environment Data Standard, v. 1.1 English Heritage, 2012. https://historicengland. org.uk/images-books/publications/midas-heritage/

National Conference of State Historic Preservation Officers [NCSHPO], "National Historic Property Inventory Initiative: Building Capacity to Preserve and Protect Our Cultural Heritage," prepared by SWCA Environmental Consultants, 2009. https://www.nps.gov/nr/publications/guidance/NHPII_Final_NP S.pdf

[U.S.] National Park Service [NPS], "National Register of Historic Places: Listed Properties, as of July 2015,” Excel spreadsheet, https://www.nps.gov/nr/research/data_downloads/ NRHP_Links_2015.xlsx Accessed 6 Dec. 2016.

\section{Notes}

1. Prior to 2016, MACRIS had only a single field for "Record Date," updated with each new form or supplementary file. Record Date became a multivariable field when Pick transitioned to SQL Server, but there are no plans to retroactively enter record events for legacy records in the 20-year old database.

2. Database Designs, Inc. of Boston took over the maintenance and design of MACRIS within a decade of its launch. 